Conclusion Protective actions for workers most susceptible to death, such as moving to activities with less exposure and/or teleworking, are necessary.

\section{P-480 CANCER MORTALITY IN MALE WORKERS EMPLOYED IN THE METALLURGICAL SHOP OF AN ENTERPRISE FOR THE BLISTER COPPER PRODUCTION}

${ }^{1}$ Natalia Zlygosteva, Vadim Adrianovskiy, Georgiy Lipatov, Alexandra Bugayeva. ${ }^{1}$ Yekaterinburg Medical Research Center for Prophylaxis and Health Protection in Industrial Workers, Russian Federation

\subsection{6/OEM-2021-EPI.349}

Introduction Currently, in Russia, malignant tumours (MT) are the second leading cause of the population mortality. Longterm, regular and intense occupational contact with exogenous chemical or physical carcinogens can lead to an occupational cancer. Occupational cancer risk assessment is required.

Objectives Revealing the influence of carcinogenic factors of the working environment on the cancer mortality rate among workmen in the metallurgical shop of an enterprise for blister copper production.

Methods A retrospective epidemiological study of cancer mortality among workmen and the population living in the area where the studied copper-smelting plant is located, for 20 years (1995-2014) was carried out. Intensive rates were calculated per 100,000 (age-specific and general, age-standardized). The so-called 'expected' mortality was calculated, which is the mortality of the 'other' population, standardized by age (in the workmen was taken as the standard). The excess of the observed cancer mortality rates determined the degree of additional risk associated with work, and made it possible to roughly estimate the intensity of the influence of production carcinogenic factors. The confidence intervals were calculated at $\mathrm{p}<0.05$.

Results The intensive cancer mortality rate in workmen for lung cancer was $495.87 \pm 201.94$ versus $120.51 \pm 19.04$ (4.1, $\mathrm{p}<0.05)$. Significantly higher in the 50-59 age group for all tumours: $\quad 1239.67 \pm 318.09$ versus $307.3 \pm 30.38 \quad$ (4.0, $\mathrm{p}<0.05)$. In the same group, the respiratory cancer mortality was significantly higher by $5.5(\mathrm{p}<0.05)$. The 'expected' cancer mortality rates in workmen had statistically significant differences in all tumour localizations are 2.3 times, and for the respiratory cancers by 4.0 times, incl. on the trachea, bronchi and lungs tumours by 3.5 times $(\mathrm{p}<0.05)$, as well as the ratio of observed cancer mortality rates to 'expected' in workmen.

Conclusion Intensive and standardized cancer mortality rates for blister copper workmen are significantly higher than control, indicating an occupational cancer hazard with the highest levels according to the highest carcinogenic load (respiratory and digestive organs).

\section{P-482 THE ROLE OF SELF-REPORTED STRESSORS IN RECOVERY FROM LONG-TERM EXHAUSTION: A LONGITUDINAL STUDY}

'Britta Eklöf, Susanne Ellbin, Ingibjörg Jonsdottir, Siobhan O'Dwyer, Caroline Hansson, Hanna Larsson. ${ }^{1}$ Norwegian University of Science and Technology, Norway

10.1136/OEM-2021-EPI.350
Introduction Stress-related exhaustion is characterized by both physical and mental symptoms of exhaustion and for many patients the prognosis seems to be long lasting. Little is known what factors may influence such long-term prognosis. One plausible explanation could be differences in exposure to certain stressors, or vulnerability related to previous life events.

Objectives The purpose of this study was to examine if work and private related stress-exposure, as well as adverse childhood experiences differ between patients that are still exhausted at a long-term follow-up, with a group of patients that have recovered from their exhaustion.

Methods Patient records from 150 patients diagnosed with Exhaustion Disorder (ED) at a specialist outpatient stress clinic was analysed regarding work- and private-related stressors, and adverse childhood experiences. The first part of data analysis consisted of a qualitative text analysis, creating a coding scheme. Frequency statistics regarding each stressor was calculated to compare the two groups. At the 7-10 year follow-up, $34 \%$ of the patients still fulfilled the criteria for ED, compared to $66 \%$ that had recovered.

Results Compared to the patients that had recovered, significantly more patients with long-term exhaustion, reported managerial responsibilities ( $8 \%$ versus $0 \%)$ and caregiver stress related to children (24\% versus $6 \%$ ) at follow-up. Significantly more recovered patients reported work related quantitative demands (73\% versus 53\%) and managerial responsibilities (14\% versus $2 \%)$ at first visit, and experienced more caregiver stress related to parents at follow-up (6\% versus 0\%). There were no differences regarding adverse childhood experiences.

Conclusions The main conclusion is that neither adverse childhood experiences nor any of the stressors at the onset of exhaustion seem to be associated with a lack of recovery. However, stressors at follow-up relating to having responsibility for other people, such as managerial responsibilities or caring for a child with a chronic disease or psychiatric disorder, may be associated with prolonged recovery.

\section{P-489 SYSTEMATIC REVIEW OF INTERVENTIONS TO MITIGATE PRECARIOUS EMPLOYMENT AND ITS EFFECTS ON THE HEALTH AND WELL-BEING OF INDIVIDUALS AND COMMUNITIES}

Virginia Gunn, 'Carin Håkansta, Bertina Kreshpaj, Emily Ahonen, Maria Albin, Sherry Baron, Christer Hogstedt, Nuria Matilla Santander, Carles Muntaner, Patricia O'Campo, Cecilia Orellana, Emilia Vignola, David H Wegman, Theo Bodin. 'Karolinska Institutet, Sweden

\subsection{6/OEM-2021-EPI.351}

Objectives The review is part of the Sweden-based research programme PWR, which consists of early-career and senior researchers in public health, occupational health as well as social sciences from a range of European countries, the United States, Canada and Chile. PWR started in 2019. The purpose of our review is to identify implemented initiatives that aim to or have the potential to eliminate, reduce or mitigate workers' exposure to precarious employment and/or its effects on the physical and mental health, health equity, safety and wellbeing of workers.

Methods We use the PRISMA guideline for systematic reviews, including its extension for equity-focused reviews. Our comprehensive search covers a combination of social, public health, medical, and public policy databases along with 